LETTER TO THE EDITOR

\title{
Vertigo and hearing loss during the COVID-19 pandemic - is there an association?
}

\author{
La vertigine e l'ipoacusia durante la pandemia COVID-19 - esiste un nesso? \\ Mahboobeh Karimi-Galougahi ${ }^{1,2}$, Ali Safavi Naeini ${ }^{1,2}$, Nasim Raad $^{1,2}$, Narges Mikaniki ${ }^{3}$, Jahangir Ghorbani ${ }^{1,2}$ \\ ${ }^{1}$ Department of Otolaryngology, Masih Daneshvari Hospital, Tehran, Iran; ${ }^{2}$ Chronic Respiratory Disease Research Center, National \\ Research Institute of Tuberculosis and Lung Diseases, Shahid Beheshti University of Medical Sciences, Tehran, Iran; ${ }^{3}$ Department of \\ Otolaryngology, Iranshahr University of Medical Sciences, Sistan and Baluchestan, Iran
}

KEY WORDS: vertigo, hearing loss, sensorineural hearing loss, COVID-19, corona virus

PAROLE CHIAVE: vertigine, ipoacusia, ipoacusia neurosensoriale, COVID-19, corona virus

\section{Dear Editor,}

Concurrent with the global outbreak of coronavirus disease-2019 (COVID-19), exceeding numbers of new cases with smell and taste disorders have been reported from Asia and Europe ${ }^{1}$, prompting the possibility of direct neuropathic effect of severe acute respiratory syndrome-coronavirus-2 (SARS-CoV-2) as the likely underlying mechanism. Post-viral olfactory dysfunction is a wellknown disease entity caused by several families of viruses, including betacoronoviridae $^{2}$. Akin to the effects of viruses on neural pathways of olfactory sense, post-viral vertigo or hearing loss are known sequelae of viruses that can cause vestibular neuritis or labyrinthitis ${ }^{3}$. For instance, the DNA of herpes simplex virus has been found in the vestibular nerve fibres in patients with vertigo secondary to vestibular neuritis ${ }^{3}$.

Whether SARS-CoV-2 can invade the neural pathways involved in the balance and hearing is not known, but initial observations implicate the possibility. A recent study in asymptomatic patients with confirmed COVID-19 revealed increased high-frequency pure-tone thresholds while transient evoked otoacoustic emissions were significantly reduced, all in the absence of otologic symptoms ${ }^{4}$. While coronaviruses have neurotropic and neuroinvasive properties ${ }^{5,6}$, after a search in the English literature we found no cases suggestive of the inner ear or vestibulocochlear nerve involvement during the SARS-CoV or Middle Eastern respiratory syndrome (MERS) outbreak.

Nevertheless, neurologic manifestations spanning the central nervous system, peripheral nervous system and skeletal muscles have been recently reported in hospitalised patients with COVID-19 ${ }^{7}$. Most neurologic manifestations occurred early in the illness and neurologic symptoms were the only presenting symptoms in some patients without other typical symptoms of COVID-19 ${ }^{7}$. The spectrum of neurologic syndromes known to be caused by COVID-19 encompasses encephalitis, meningitis, demyelination and Guillain-Barre syndrome ${ }^{7,8}$. Thus, SARS-CoV-2 neurotropism may make it possible to inflict a wide spectrum of neuropathic effects, potentially including effects on neural networks governing hearing and balance.

In addition to a direct cytopathic effect of the virus, inflammatory response,
Received: May 1, 2020

Accepted: May 18, 2020

Published online: June 10, 2020

Correspondence

Jahangir Ghorbani

Department of Otolaryngology, Masih Daneshvari

Hospital, Neyavran, Daar Abad, Tehran, Iran

Tel. +98 21 26105242. Fax +982126105242

E-mail: jghorbani@sbmu.ac.ir

Funding

None.

Conflict of interest

The Authors declare no conflict of interest.

How to cite this article: Karimi-Galougahi $\mathrm{M}$, Naeini AS, Raad N, et al. Vertigo and hearing loss during the COVID-19 pandemic - is there an association? Acta Otorhinolaryngol Ital 2020;40:463-465. https://doi. org/10.14639/0392-100X-N0820

() Società Italiana di Otorinolaringoiatria e Chirurgia Cervico-Facciale

\section{cc) (1) $(9$}

This is an open access article distributed in accordance with the CC-BY-NC-ND (Creative Commons Attribution-NonCommercial-NoDerivatives 4.0 International) license. The article can be used by giving appropriate credit and mentioning the license, but only for non-commercial purposes and only in the original version. For further information: https:// creativecommons.org/licenses/by-nc-nd/4.0/deed.en 
Table I. Demographic and clinical characteristics of patients with acute hearing loss or vertigo and high clinical suspicion for/or confirmed coronavirus disease-2019 (COVID-19).

\begin{tabular}{|c|c|c|c|c|c|c|c|c|c|c|c|c|c|c|}
\hline \multirow[t]{2}{*}{$\mathrm{N}$} & \multicolumn{4}{|c|}{$\begin{array}{l}\text { Demographic and clinical } \\
\text { characteristics }\end{array}$} & \multirow[t]{2}{*}{$\begin{array}{l}\text { General } \\
\text { symptoms }\end{array}$} & \multicolumn{3}{|c|}{ Otologic or balance symptoms } & \multicolumn{6}{|c|}{ Pure tone audiometry - bone (dB) } \\
\hline & Sex & $\begin{array}{c}\text { Age } \\
\text { (years) }\end{array}$ & $\begin{array}{c}\text { FH of } \\
\text { COVD-19 }\end{array}$ & PCR & & Tinnitus & Vertigo & $\begin{array}{c}\text { Laterality } \\
\text { of } \\
\text { hearing } \\
\text { loss }\end{array}$ & 500 & 1000 & 2000 & 3000 & 4000 & 8000 \\
\hline 1 & $F$ & 34 & - & Pending & $\begin{array}{l}\text { Dyspnoea, } \\
\text { Cough }\end{array}$ & - & Slight & Right & 0 & 0 & 0 & 20 & 60 & 90 \\
\hline 3 & $\mathrm{~F}$ & 40 & - & + & $\begin{array}{c}\text { Dyspnoea, } \\
\text { Cough, } \\
\text { Malaise }\end{array}$ & + & - & Right & 50 & 60 & 60 & 60 & 65 & 80 \\
\hline 4 & $M$ & 38 & - & - & $\begin{array}{c}\text { Dyspnoea, } \\
\text { Cough, } \\
\text { Fever }\end{array}$ & + & - & Right & 40 & 50 & 55 & 60 & 70 & 80 \\
\hline 6 & F & 35 & - & - & $\begin{array}{c}\text { Dyspnoea, } \\
\text { Cough, } \\
\text { Fever }\end{array}$ & + & - & Right & 40 & 40 & 45 & 45 & 50 & 60 \\
\hline
\end{tabular}

dB: decibel, FH: family history, N: number, PCR: polymerase chain reaction

cytokine storm and cerebrovascular events ${ }^{7,8}$, especially in the posterior circulation ${ }^{9}$, and ototoxic drugs like azithromycin, hydroxychloroquine being used extensively during the nascent pandemic as therapeutic agents may also contribute to hearing or balance disorders associated with COVID-19. Anecdotally, during recent weeks, we have frequently encountered patients without previous otologic or neurologic problems who presented with true vertigo or sensorineural hearing loss. While initially none of these cases were tested for COVID-19 due to the scarcity of the screening tests and the priority given to the patients with typical symptoms or severe form of COVID-19, some had family members with recent history of COVID-19, with the universal concomitant presence of symptoms such as fever, cough and dyspnoea, pointing to high clinical suspicion for COVID-19 that in some patients (e.g., patient number 6 in Tab. I) led to diagnosis of COVID-19 on chest computed tomography.

Recently, we have been able to perform polymerase chain reaction (PCR) assay to confirm COVID-19 in a number of patients with acute-onset hearing loss and/or vertigo (Tab. I). Since these young patients (age range 22-40 years) had no previous relevant medical history and had not received any ototoxic drugs prior to their presentation, it is highly likely that these otologic symptoms are directly related to/ caused by COVID-19, especially since pure tone audiometry revealed a sensory-neural mechanism for the unilateral hearing loss (Tab. I).
These recent confirmed cases of COVID-19, the anecdotal epidemiological correlations and bio-pathological mechanisms call for urgent studies to examine the association of new onset otologic symptoms with COVID-19 during the current pandemic. There are several important issues to address. First priority is in performing screening PCR tests, which are hoped to become more widely available than during the early phase of the pandemic, to establish a link, especially in cases with isolated hearing loss or balance disorder. Absent the availability of PCR assay, and if the hearing or balance problems are not associated with respiratory symptoms, it is debatable whether imaging such as chest computed tomography should be considered, although with an increasing number of "clinically silent" cases of pulmonary involvement with SARS-CoV-2 being recognised, this approach may be clinically justifiable. Last, apart from implications on the need for patient isolation, there are immediate therapeutic dilemmas including the use of local or systemic steroids and whether empiric antivirals should be considered.

\section{References}

1 Lechien JR, Chiesa-Estomba CM, De Siati DR, et al. Olfactory and gustatory dysfunctions as a clinical presentation of mild to moderate forms of the Coronavirus disease (COVID-19): a multicenter European study. Eur Arch Otorhinolaryngol 2020;277:2251-61. https:// doi.org/10.1007/s00405-020-05965-1 
2 Passioti M, Maggina P, Megremis S, et al. The common cold: potential for future prevention or cure. Curr Allergy Asthma Rep 2014;14:413. https://doi.org/10.1007/s11882-013-0413-5

3 Goddard JC, Fayad JN. Vestibular neuritis. Otolaryngol Clin N Am 2011;44:361-5. https://doi.org/10.1016/j.otc.2011.01.00

4 Mustafa MWM. Audiological profile of asymptomatic Covid-19 PCR-positive cases. Am J Otolaryngol 2020;41:102483. https://doi. org/10.1016/j.amjoto.2020.102483

5 Li YC, Bai WZ, Hashikawa T. The neuroinvasive potential of SARSCoV2 may be at least partially responsible for the respiratory failure of COVID-19 patients. J Med Virol 2020;92:552-5. https://doi. org/10.1002/jmv. 25728

6 Netland J, Meyerholz DK, Moore S, et al. Severe acute respiratory syndrome coronavirus infection causes neuronal death in the ab- sence of encephalitis in mice transgenic for human ACE2. J Virol 2008;82:7264-75. https://doi.org/10.1128/JVI.00737-08

7 Mao L, Jin H, Wang M, et al. Neurologic manifestations of hospitalized patients with Coronavirus disease 2019 in Wuhan, China. JAMA Neurol 2020;77:683-90. https://doi.org/10.1001/jamaneurol.2020.1127

8 Ashrafi MR, Azizimalamiri R, Badv RZ, et al. Coronavirus, its neurologic manifestations, and complications. Iran J Pediatr Epub 2020;30:e102569. https://doi.org/10.5812/ijp.102569

9 Venhovens J, Meulstee J, Verhagen WIM. Acute vestibular syndrome: a critical review and diagnostic algorithm concerning the clinical differentiation of peripheral versus central aetiologies in the emergency department. J Neurol 2016;263:2151-7. https://doi.org/10.1007/ s00415-016-8081-8 